\title{
MONITORAMENTO TECNOLÓGICO SOBRE BIOREFINARIAS A PARTIR DE FONTES DE MATÉRIA-PRIMA RENOVÁVEL
}

\author{
MONITORING TECHNOLOGY ON BIOREFINERIES FROM SOURCES OF \\ RENEWABLE RAW MATERIAL
}

\section{Márcia França Ribeiro Fernandes dos Santos}

Suzana Borschiver

Maria Antonieta Peixoto Gimenes Couto

\begin{abstract}
RESUMO:
O recente aumento das cotações internacionais do petróleo, as perspectivas de esgotamentos de suas reservas, os riscos geopolíticos decorrentes da dependência desta commodity de países instáveis politicamente e a maior preocupação com a questão ambiental desde a assinatura do Protocolo de Quioto puseram em evidência as fontes alternativas de energia, como o etanol e o biodiesel em um contexto de integrado de biorefinarias. Especialistas acreditam que as biorefinarias possam se tornar uma indústria-chave do século XXI, responsável até mesmo por uma nova revolução industrial, face a importância das tecnologias que empregam e dos efeitos sobre o paradigma industrial. Tais tecnologias são fundamentadas na utilização de toda a planta e na integração de processos tradicionais e modernos de utilização de matérias-primas biológicas.
\end{abstract}

Palavras-chave: Biorefinaria. Matéria-prima renovável. Etanol. Biodiesel.

\section{ABSTRACT:}

The recent volatility in international oil prices, the prospect of depletion of its reserves, geopolitical risks arising from this commodity dependence of politically unstable countries and greater focus on environmental issues since the signing of the Kyoto Protocol have highlighted the alternative sources of energy such as ethanol and biodiesel in a context of integrated of biorefineries. Experts believe that biorefineries.can become a key industry of the twenty-first century, even responsible for a new industrial revolution, due to the importance of technology they employ and the effects on the industrial paradigm. These technologies are based on the use of the entire plant and the integration of traditional and modern procedures for the use of renewable raw materials.

Key words: Biorefineries. Renewable raw material. Ethanol. Biodiesel. 


\section{INTRODUÇÃO}

Atualmente, a química e a tecnologia química são um dos pilares da moderna civilização,porque atendem muitas das necessidades vitais da sociedade e oferecem numerosos benefícios à humanidade. Segundo Machado (2004 p.61) "a contribuição da química para a vida das pessoas no século XXI continuará a ter um largo alcance e a envolver uma grande variedade de modos de atividade positivos". Entretanto, para satisfazer este papel, reconhece-se que é de vital relevância que a química e a tecnologia química sejam seguras, úteis e desfrutem da confiança das pessoas.

Esta idéia vem ao encontro do novo paradigma de desenvolvimento denominado sustentável que é definido no Relatório de Bruntland (INDICADORES DE DESENVOLVIMENTO SUSTENTAVEL, 2004) como aquele que atende as necessidades do momento presente sem o comprometimento de que as gerações futuras atendam as suas próprias necessidades. De acordo com este novo paradigma o grau de avanço de uma sociedade é auferido não somente pela sua capacidade de gerar riqueza - dimensão econômica, mas também pelas condições de divisão da riqueza gerada - dimensão social - juntamente com a preservação e conservação do meio ambiente - dimensão ambiental (RIBEIRO et al, 2007).

Neste contexto, houve o surgimento da chamada Química Verde ou Sustentável que se refere à prática da química com objetivos de proteger o ambiente e a saúde da bioesfera, incluindo os seres humanos (MACHADO, 2004). A mesma pode contribuir decisivamente para se construir uma sociedade sustentável e proporcionar uma base para se trabalhar na procura de um futuro sustentável. Para isto é necessário que todas as pessoas associadas com a química e a tecnologia química se engajem neste movimento verde. Como exemplos de química sustentável se pode citar: (i) fabricação e comercialização de produtos que não sejam nocivos ao meio ambiente e a saúde dos seres vivos; (ii) utilização de tecnologias limpas, que não produzam resíduos tóxicos; (iii) uso de matérias-primas provenientes de recursos naturais renováveis; (iv) utilização de energias renováveis, etc.

Estes dois últimos aspectos são motivadores para a disseminação da idéia da sustentabilidade na indústria química que é fundamentada no binômio matéria e energia. Segundo Borschiver (2006) a Organização de Cooperação de Desenvolvimento Econômico (OCDE) vem buscando difundir a idéia de uma química sustentável, fundamentada em matérias-primas renováveis e mais eficiente do ponto de vista energético.

Esforços em pesquisa tecnológica estão sendo realizados para a utilização de biomassa para fins energéticos, com destaque para seu uso na geração de combustíveis. A título de exemplos de biomassa para tais fins menciona-se: a cana-de-açúcar de onde se extrai o álcool; o biogás produzido a partir da biodegradação anaeróbica no lixo orgânico; e alguns óleos vegetais como o de mamona, soja de onde se extrai o biodiesel (RAMOS, 2003 apud RATHMANN ET al, 2006).

Inserido neste cenário, surge o conceito de biorefinaria que segundo Jong et al (2005 p. 11) "é uma facilidade que integra os processos de conversão de biomassa e equipamentos para a coprodução de combustíveis, energia e produtos químicos provenientes de diversas fontes de biomassa". A biorefinaria pode ser concebida como uma estrutura análoga às refinarias de petróleo que produzem múltiplos combustíveis e produtos oriundos do petróleo; nas biorefinarias industriais identificam rotas promissoras com vistas à criação de uma economia baseada em produtos renováveis (REALFF \& ABBAS, 2004 apud JONG ET AL, 2005). 
0 presente trabalho faz parte de uma tese de doutorado em andamento que tem como objetivo principal a realização de um monitoramento tecnológico e mercadológico sobre biorefinarias, no Brasil e no mundo, com a identificação de diversas questões, tais como: a evolução de seu

desenvolvimento tecnológico; quem são os principais países, instituições e empresas que estão realizando tais pesquisas; o que está sendo pesquisado por área do conhecimento; e quais são as principais matérias-primas utilizadas e produtos obtidos.

\section{INFORMAÇÕES SOBRE BIOREFINARIA}

De acordo com Fernando et al (2006) o conceito de produzir produtos a partir de commodities agrícolas, como a biomassa, não é novo; no entanto, utilizar a biomassa como insumo na produção de vários produtos de maneira similar a uma refinaria de petróleo onde combustíveis fósseis são usados como input é relativamente novo.

Seu principal objetivo é transformar os materiais biológicos em produtos utilizáveis nas indústrias de transformação usando uma combinação de tecnologias e processos biotecnógicos (FERNANDO et al, 2006). A Figura 1 apresenta os elementos de uma biorefinaria em que as fontes de biomassa são usadas para produzir vários produtos como combustíveis, energia e produtos químicos por meio de processos de conversão biológicos e químicos.

Figura 1 - Diagrama de uma biorefinaria - biomassa - processo - produto

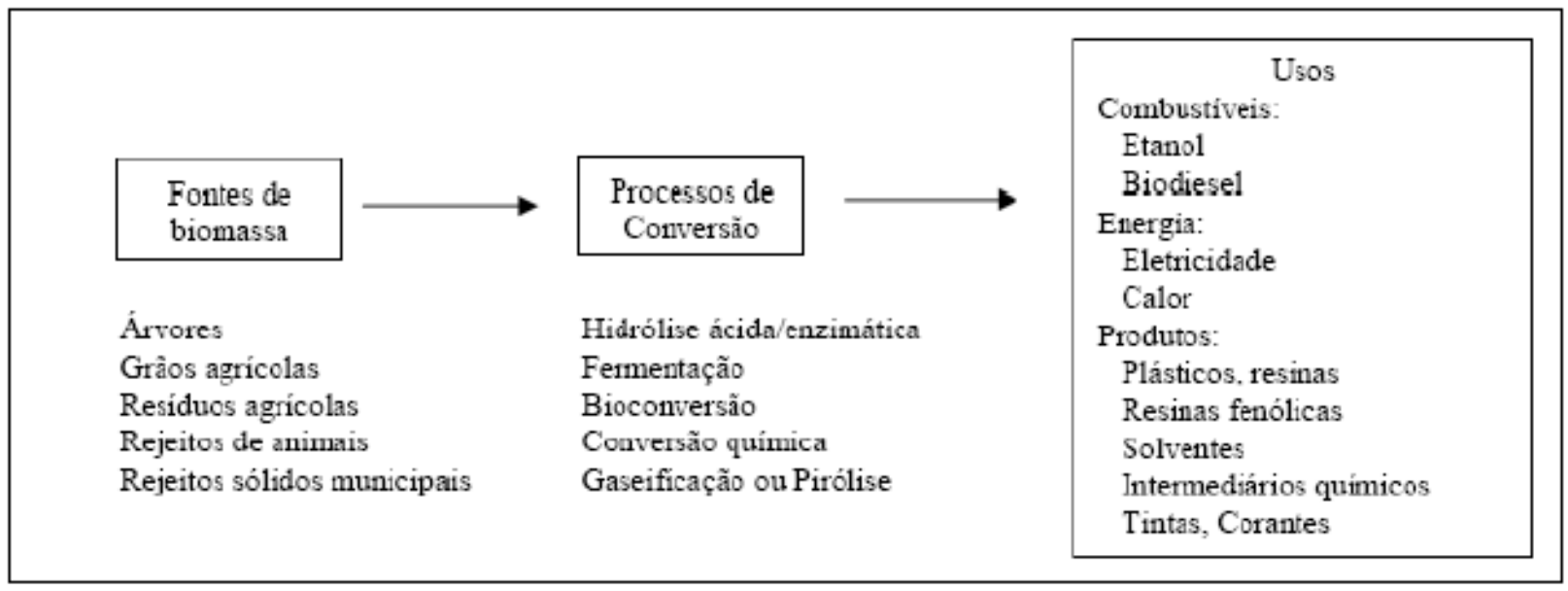

Fonte: FERNANDO et al (2006)

Em seus estudos Kamm et al (2004 apud FERNANDO et al, 2006) e Van Dyne et al (1999 apud FERNANDO et al, 2006) apontam a existência de três tipos de biorefinarias, que ainda estão na fase de pesquisa e desenvolvimento: (i) biorefinaria agrícola; (ii) biorefinaria verde; e (iii) biorefinaria a partir de materiais lignocelulósicos.

A biorefinaria agrícola processa e consome o grão inteiro para a obtenção do produto desejado. 0 processo de conversão da biomassa e energia é iniciado pela separação mecânica da biomassa em componentes diferentes que são tratados separadamente. Como exemplo, pode ser citado a produção de etanol a partir do milho (FERNANDO et al, 2006).

A biorefinaria verde é um conceito que utiliza a biomassa (por exemplo, plantas verdes e grãos) industrialmente para gerar produtos químicos (como ácido lático e aminoácidos), 
produtos de química fina, fibras e energia oriunda da geração de biogás (HALASZ et al, 2005). A primeira etapa deste tipo de refinaria é o tratamento da biomassa verde em que há a produção de torta prensada rica em fibra e um suco verde rico em nutrientes. A torta prensada contém substâncias como celulose, amido, corantes e pigmentos que podem servir de matérias-primas para a produção de produtos químicos; enquanto o suco verde inclui proteínas, aminoácidos livres, ácidos orgânicos, corantes, enzimas dentre outras substâncias que podem servir de insumos para a produção de ácido lático e etanol por exemplo (FERNANDO et al, 2006).

A biorefinaria a partir de materiais lignocelulósicos, aquela mais desenvolvida, usa um mix de fontes de biomassa para a produção de uma série de produtos por meio de uma combinação de tecnologias. Tal biorefinaria consiste de três frações química básicas: (a) hemicelulose, polímeros de açúcar com cinco carbonos; (b) celulose, polímeros de glucose com seis carbonos; e (c) lignina, polímeros de fenol (FERNANDO et al, 2006).

Inicialmente, o insumo é limpo e quebrado em três frações - hemicelulose, celulose e lignina por meio de digestão química ou hidrólise enzimática. A fração de xilose da hemicelulose pode ser convertida em furfural que é um dos insumos para a produção do nylon 6 (KAMM ET al, 2004 apud FERNANDO et al, 2006), além de poder ser usado no refino de óleos de motores.

Já a hidrólise da celulose em glucose pode ser realizada tanto por processamento enzimático como químico com a produção de produtos como etanol, ácido acético, acetona, butanol, ácido succníco e outros produtos da fermentação. A lignina, não apresenta numerosos usos como a hemicelulose e a celulose; atualmente, a lignina tem usos limitados como adesivo ou liga (FERNANDO et al, 2006).

\section{METODOLOGIA}

Foi utilizada como fonte de dados o banco de publicações do ISI Web of Knowledge, denominado Web of Science, acessada via portal de periódicos da Coordenação de Aperfeiçoamento de Pessoal de Nível Superior (CAPES) (www.periodicos.capes.gov.br) de acordo com os parâmetros de busca especificados na Tabela 1.

Tabela 1 - Parâmetros de busca na base de dados Web of Science

\begin{tabular}{|l|}
\hline Parâmetros de busca \\
\hline - Topic Search: biorefinery \\
- DocType: All document types \\
- Languages: All languages \\
- Databases: SCI-EXPANDED, SSCI, A\&HCI \\
- Timespan: 1945 - 2007 \\
- Country/Territory: All \\
\hline
\end{tabular}

Ao final da pesquisa, foram identificadas um total de 131 publicações - como artigos, resumos de encontro, editorial; cabendo destacar que deste quantitativo 98 são artigos. Tais publicações foram analisadas mais detalhadamente, através da leitura dos resumos 
disponibilizados, para o monitoramento das questões objeto de estudo.

\section{RESULTADOS E DISCUSSÃO}

A Figura 2 apresenta a evolução do número de publicações ao longo do tempo com relação ao tema biorefinaria. A primeira publicação relacionada a este tema ocorreu no ano de 1988 e a segunda somente em 1993. Tal Figura 2 revela que esta tecnologia apresenta um interesse crescente por parte da comunidade científica, principalmente a partir do ano de 2004 .

Figura 2 - Evolução das publicações sobre biorefinaria - período de 1945-2007

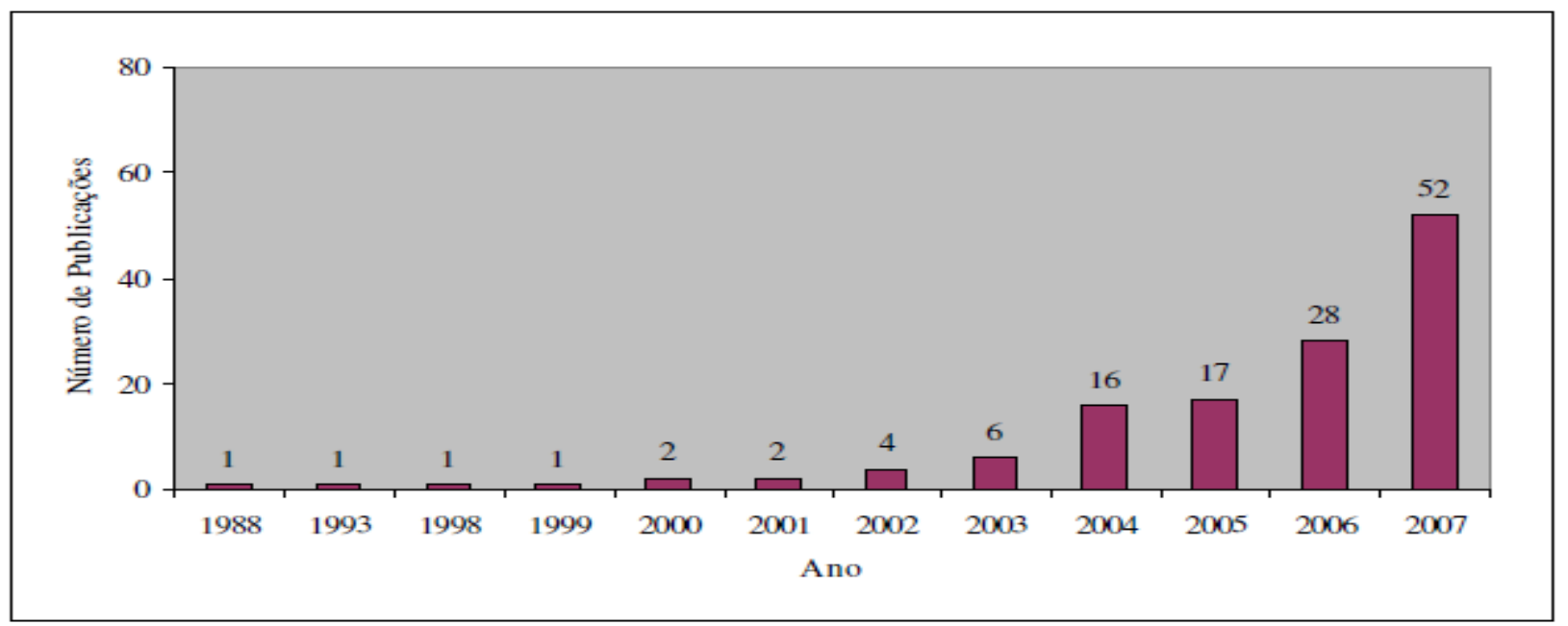

A Figura 3 mostra a distribuição dos países quanto à autoria das publicações para o período de tempo analisado. Tal distribuição por países apontou os Estados Unidos (EUA) como o principal responsável pela maior parte das publicações sobre biorefinaria, respondendo por mais de $32 \%$ do total destas, seguido por Canadá, Alemanha e Inglaterra com aproximadamente $11 \%, 11 \%$ e $10 \%$ respectivamente. Cabe destacar que no banco de dados consultado foi encontrada apenas uma publicação de origem brasileira.

Figura 3 - Distribuição dos países quanto à autoria das publicações sobre biorefinaria período1945-2007

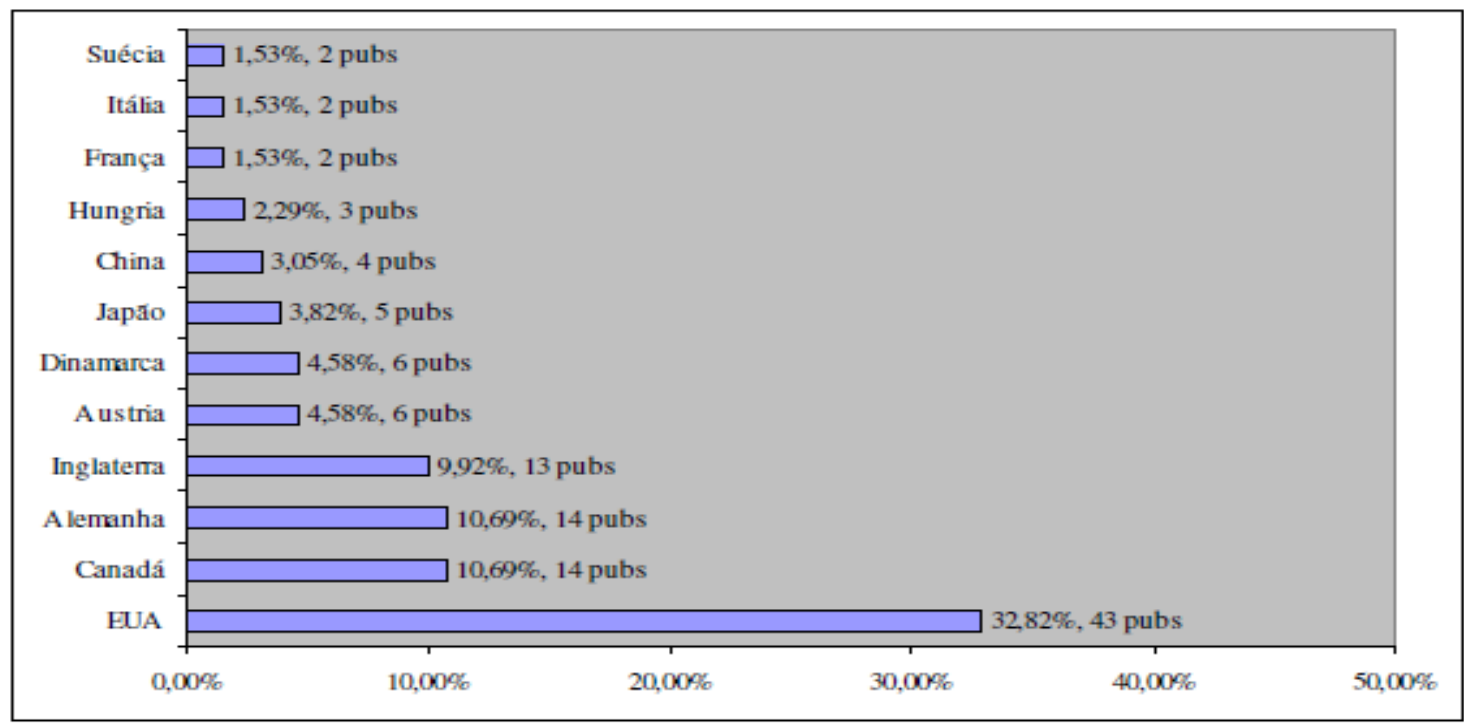


A Figura 4 ilustra a distribuição por tipos de instituições que desenvolveram pesquisas sobre o tema em questão. 0 estudo revelou a grande participação das universidades (65\%), seguida das empresas (29\%) e dos centros de pesquisa/institutos/laboratórios (23\%). A Universidade British Columbia, localizada no Canadá, foi aquela com o maior respeito de biorefinarias, totalizando oito publicações.

Figura 4 - Distribuição por tipos de instituições quanto à autoria das publicações sobre biorefinaria - período 1945-2007

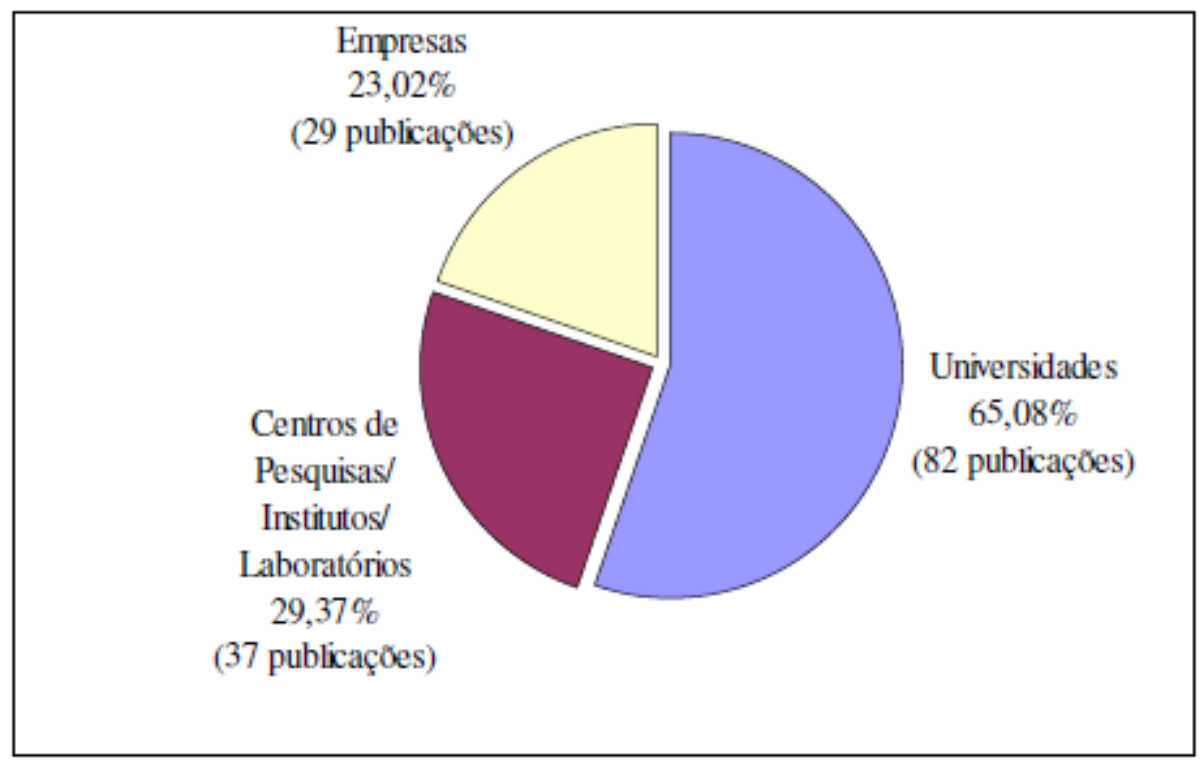

A Figura 5 apresenta a distribuição por áreas de conhecimento das publicações sobre o assunto analisado. Os dados obtidos revelam que as pesquisas se concentram na área de biotecnologia e microbiologia aplicada, considerando que 40,46\% das publicações encontradas são classificadas em tal área do conhecimento, seguida de química multidisciplinar e engenharia química com 19,08\% e 15,27\% respectivamente.

Figura 5 - Distribuição por áreas do conhecimento das publicações sobre biorefinaria período 1945-2007

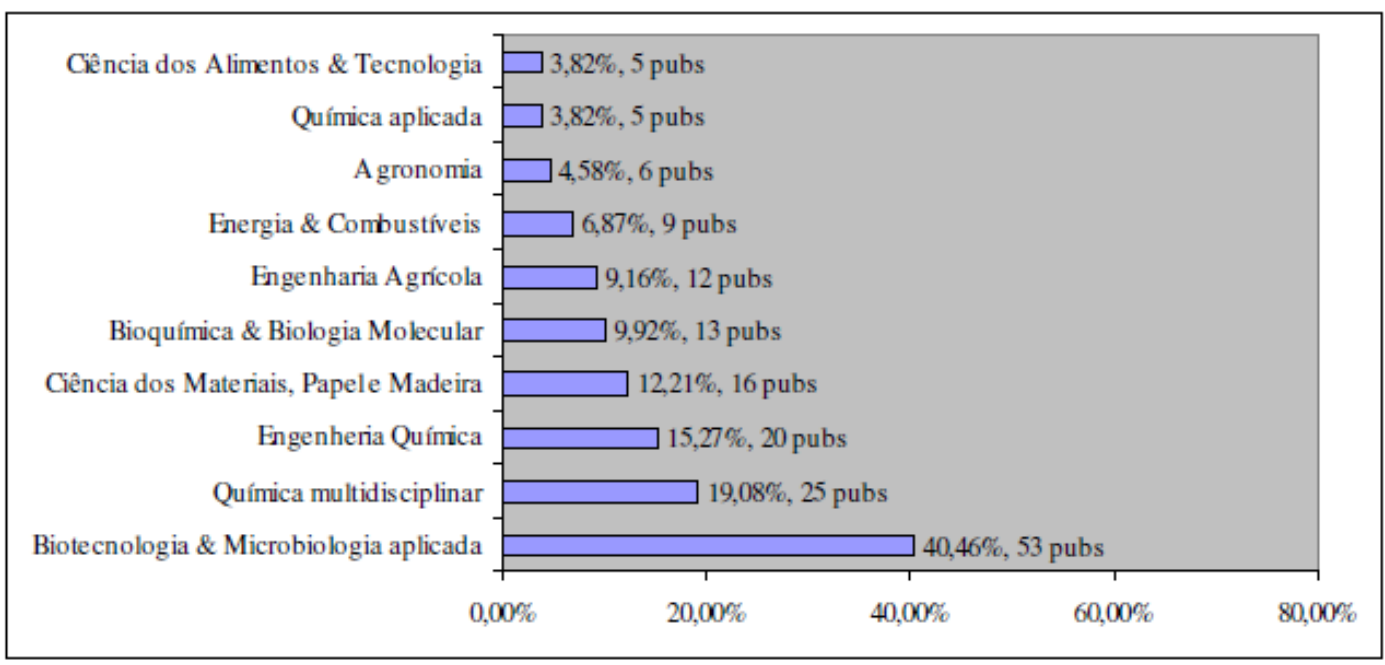


A Tabela 2 mostra o ranking com as matérias-primas utilizadas nas biorefinarias de acordo com a base de dados consultada. 0 estudo revela que o material lignocelulósico é o principal insumo para os produtos obtidos nas biorefinarias de acordo com mais de $30 \%$ das publicações encontradas. Cabe destacar que tais materiais foram classificados em: resíduos do milho, açúcar, arroz e batata; resíduos da madeira; resíduos agrícolas; resíduos florestais e geral (quando não havia uma identificação específica da matéria-prima).

Tabela 2 - Ranking das matérias-primas utilizadas nas biorefinarias - período 1945-2007

\begin{tabular}{lcc}
\hline Matérias-primas & $\begin{array}{l}\mathrm{N}^{\circ} \\
\text { Publicações }\end{array}$ & de Percentual sobre 131 publicações \\
\hline $\begin{array}{l}\text { Material lignocelulósico } \\
\text { resíduos do milho, açúcar, arroz, }\end{array}$ & 40 & $30,53 \%$ \\
batata & 10 & $7,63 \%$ \\
resíduos de madeira & 8 & $6,11 \%$ \\
resíduos agrícolas & 2 & $1,53 \%$ \\
resíduos florestais & 4 & $3,05 \%$ \\
geral & 16 & $12,21 \%$ \\
Milho & 3 & $2,29 \%$ \\
Óleo vegetal (canola, algodão) & 3 & $2,29 \%$ \\
\hline
\end{tabular}

A Tabela 3 apresenta o ranking dos processos químicos utilizados nas biorefinarias em conformidade com a base de dados consultada. A pesquisa aponta que o processo biotecnológico mais utilizado nas biorefinarias é a fermentação (mais de $22 \%$ de uso), seguido da hidrólise (com um pouco mais de 12\%).

Tabela 3 - Ranking dos processos químicos utilizados nas biorefinarias - período 1945-2007

\begin{tabular}{lccc}
\hline Processos Químicos & $\begin{array}{l}\mathbf{N}^{\circ} \\
\text { Publicações }\end{array}$ & $\begin{array}{l}\text { de Percentual } \\
\text { publicações }\end{array}$ \\
\hline Fermentação & 30 & $22,90 \%$ \\
Hidrólise & 17 & $12,98 \%$ \\
Pirólise & 5 & $3,82 \%$ \\
Biosíntese & 3 & $2,29 \%$ \\
Gasificação & 3 & $2,29 \%$ \\
Organosolv & 3 & $2,29 \%$ \\
Hidrogenação & 2 & $1,53 \%$ \\
Sacarificação & 2 & $1,53 \%$ \\
Bioconversão microbiana & 1 & $0,76 \%$ \\
Catálise & 1 & $0,76 \%$ \\
Ativação por microondas & 1 & $0,76 \%$ \\
Nanofiltração & 1 & $0,76 \%$ \\
Ultrafiltração & 1 & $0,76 \%$ \\
Esterificação & 1 & $0,76 \%$ \\
Extração enzimática & 1 & $0,76 \%$ \\
\hline
\end{tabular}


Por fim, na Tabela 4 aponta o ranking dos produtos obtidos nas biorefinarias de acordo com a base de dados consultada. As informações apontam que o bioetanol é o principal produto obtido na biorefinaria, aparecendo em quase $23 \%$ das publicações encontradas. Cabe destacar ainda a presença de outros produtos como o ácido lático $(9,16 \%)$, a lignina $(8,40 \%)$, a hemicelulose $(6,87 \%)$ e a celulose $(6,11 \%)$.

Tabela 4 - Ranking dos produtos obtidos nas biorefinarias - período 1945-2007

\begin{tabular}{lccc}
\hline Produtos & $\mathbf{N}^{\text {o }}$ & \multicolumn{1}{c}{$\begin{array}{c}\text { de Percentual } \\
\text { Publicações }\end{array}$} & sobre \\
publicações \\
\hline Bioetanol & 28 & $21,37 \%$ \\
Acido lático & 12 & $9,16 \%$ \\
Lignina & 11 & $8,40 \%$ \\
Hemicelulose & 9 & $6,87 \%$ \\
Celulose & 8 & $6,11 \%$ \\
Carboidratos & 6 & $4,58 \%$ \\
Aminoácido & 5 & $3,82 \%$ \\
Proteínas & 5 & $3,82 \%$ \\
Óleos & 4 & $3,05 \%$ \\
Acido acético & 3 & $2,29 \%$ \\
Glucano & 3 & $2,29 \%$ \\
Glucose & 3 & $2,29 \%$ \\
Lipídios & 3 & $2,29 \%$ \\
Xilose & 3 & $2,29 \%$ \\
\hline
\end{tabular}

\section{CONCLUSÕES}

0 presente estudo teve como objetivo principal a realização de um monitoramento tecnológico e mercadológico sobre biorefinarias, a partir da base de dados Web of Science, com a identificação de diversas questões, tais como: a evolução de seu desenvolvimento tecnológico; quem são os principais países, instituições e empresas que estão realizando tais pesquisas; o que está sendo pesquisado por área do conhecimento; e quais são as principais matérias-primas utilizadas e produtos obtidos.

A pesquisa revelou que as primeiras publicações a respeito do tema foram publicadas no final dos anos 80, havendo a partir do ano de 2004 um crescente aumento no número de publicações sobre biorefinaria. Observa-se que mais de $64 \%$ das publicações sobre biorefinaria tiveram como país de origem os EUA, Canadá, Alemanha e Inglaterra. Quanto aos tipos de instituições que desenvolvem pesquisas sobre o tema, as universidades foram as que tiveram o maior número de publicações, seguida dos centros/institutos e laboratórios de pesquisas.

Com relação ao que está sendo pesquisado por área do conhecimento, os dados obtidos revelam que as pesquisas sobre biorefinaria se concentram na área de biotecnologia e microbiologia aplicada, considerando que $40,46 \%$ das publicações encontradas são classificadas em tal área do conhecimento. 
As publicações ainda revelam que as principais matérias-primas utilizadas são os materiais lignocelulósicos, oriundos de resíduos agrícolas, de madeira e florestais. Os processos biotecnológicos que vêm sendo mais estudados são a fermentação e a hidrólise citados em $22,90 \%$ e $12,98 \%$ das publicações respectivamente. Por fim, quanto aos principais produtos das biorefinarias destaca-se o bioetanol.

De uma maneira geral através do estudo realizado é possível perceber que as publicações estão sendo direcionadas para pesquisa e desenvolvimento das chamadas biorefinarias a partir de materiais lignocelulósicos, que utiliza um mix de fontes de biomassa para a produção de produtos químicos, energia e combustível. Ainda há muito o que se pesquisar, especialmente com relação a fração de lignina que apresenta uso limitado.

Por fim, o conceito de biorefinarias integradas tem se consolidado em âmbito mundial face às pressões de cunho ambiental-social-econômico. Embora ainda existam barreiras de natureza técnico-econômica para o desenvolvimento comercial desta nova tecnologia, a ênfase das pesquisas parece indicar que a implantação de biorefinarias é um caminho a ser adotado como resposta a tais pressões.

\section{REFERÊNCIAS}

BORSCHIVER, S. (2006) Desafios da Sustentabilidade. Revista Brasileira de Engenharia Química. Dezembro. p. 24-25.

FERNANDO, S.; ADHIKARI, S.; CHANDRAPAL, C.; MURALI, N (2007). Biorefineries: Current Status, Challenges and a Future Direction. Energy \& Fuels, v. 20, p. 1727-1737.

HALASZ, L.; POVODEN, G.; NARODOSLAWSKY, M. (2005) Sustainable processes synthesis for renewable resources. Resources, Concervation and Recycling, v. 44, p. 293-307.

INDICADORES DE DESENVOLVIMENTO SUSTENTÁVEL: Brasil 2004 (2004). Rio de janeiro: IBGE. 400 p. (Estudos e pesquisa. Informação geográfica, n.4).

JONG, E.; REE R.; TUIL, R.F.; ELBERSEN, W (2005). Biorefineries for the Chemical Industry - A Dutch point of view. In: Proceedings of the 2005 annual meeting of the association for the Advancement of Industrial Crops: International Conference on Industrial Crops and Rural Development, 17-21 September, Murcia, Spain.

MACHADO, A.A.S.C (2004). Química e Desenvolvimento Sustentável - QV, QUIVES, QUISUS? Boletim SPQ, $94, \quad 59 . \quad$ Disponível em: http://www.spq.pt/boletim/docs/boletimSPQ_095_059_09.pdf>.

RATHMANN, R; BENEDETTI, O; PLÁ, J.A. \& PADULA, A.D. (2006) Biodiesel: uma alternativa estratégica na matriz energética brasileira? In: I Congresso da Rede de Tecnologia de Biodiesel. Disponível em: <http://www.biodiesel.gov.br/docs/ArtigoBiodieselGINCOBUFRGS. pdf>.

RIBEIRO, MF; PEIXOTO, JAA; XAVIER, LS; DIAS, LMM (2007). Avaliação crítica de indicadores de desenvolvimento sustentável: uma comparação entre a estrutura adotada no Brasil e na Suíça. In: IX Encontro Nacional sobre Gestão Empresarial e Meio Ambiente, Curitiba, PR. 19 a 21 de novembro. 